\title{
ORIGINAL ARTICLE The risk factors of 9-year follow-up on hypertension in middle- aged people in Tujia-Nationality settlement of China
}

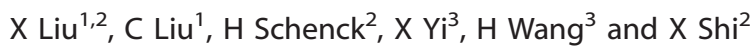

The aim of this study was to investigate the risk factors of hypertension in middle-aged people within the Tujia-Nationality settlement in China. Demographics questionnaires and fitness tests were performed to identify the risk factors of hypertension in middle-aged people in the years 2005, 2010 and 2014 in the area of southwest Hubei of China. Of the 2428 participants, 568 were classified as hypertensive, giving an overall occurrence of hypertension at $23.4 \%$, and the prevalence of hypertension was the highest in the year 2014 (34.9\%). Furthermore, Tujia minority had a significantly higher risk for having hypertension (odds ratio $=1.055$ with $95 \%$ confidence interval $(\mathrm{CI}): 1.039-1.072 ; P=0.001)$ than Han people. Individuals with the lowest level of cardiorespiratory fitness (CRF) had a 2.483 -fold risk for hypertension ( $95 \% \mathrm{Cl}, 1.530-4.031 ; P=0.001)$. Obesity and overweight individuals increased the risk by 3.470 -fold and 2.124-fold, respectively, for having hypertension compared to normal weight people. Finally, white-collar workers had a 58.1 and $31.8 \%$ higher risk for hypertension than blue-collar workers in rural and urban areas, respectively. These results demonstrated that the prevalence of hypertension was higher between 2011 and 2014 in the area. The main risk factors for developing hypertension were found to be sex (as woman), Tujia minority, white-collar workers, overweight-obese, those with a middle school education, and those with the lowest CRF.

Journal of Human Hypertension (2017) 31, 838-842; doi:10.1038/jhh.2017.58; published online 10 August 2017

\section{INTRODUCTION}

Hypertension is one of the most common medical disorders, affecting one in four adults worldwide, with a lifetime prevalence that may exceed $90 \%{ }^{1}$ Hypertension is associated with increased risks of stroke, ischaemic heart disease, heart failure, kidney disease and premature mortality. ${ }^{2}$ There are many factors in the aetiology of essential hypertension, but it can vary between ethnicities, ${ }^{3}$ countries ${ }^{4}$ or even among regions within the same country. ${ }^{5}$

The Tujia-Nationality settlement in the southwest Hubei province in China is the most poverty stricken area in the Hubei province; however, utilization of the highway and railway systems during the past 5 years has rapidly improved the economy of the area. Middle-aged people encounter intense pressure regarding any changes in the economy, which is a main factor of many chronic diseases. ${ }^{6}$ However, to our knowledge, few studies focus on the changes of chronic diseases in this area, particularly hypertension. This study examined arterial blood pressure and cardiopulmonary fitness of the middle-aged people in the years 2005, 2010 and 2014 to identify the prevalence of hypertension and its distribution, as well as the risk factors within the TujiaNationality settlement area.

\section{MATERIALS AND METHODS}

\section{Study population}

This study consisted of three cross-sectional surveys in the years 2005, 2010 and 2014, which was initiated and sponsored by the All-China Sports Federation and the Ministry of Health of the People's Republic of China, and supported and approved by the local government and the University for Nationalities in Enshi, Hubei province. This study was designed to investigate the risk factors of hypertension in the southwest Hubei province of China. A total of 2428 middle-aged $45-59$ years old men and women ( $n=633$ in 2005, $n=844$ in 2010 and $n=951$ in 2014) who voluntarily provided the informed consent participated in this study. All participants were recruited from the same Tujia settlement area in Hubei province of China.

\section{Methods}

The tests were comprised of two parts: a demographics questionnaire and a fitness test. Questionnaires inquired about age, nationality, gender, urban versus rural location, employment classification and highest level of completed education. Fitness testing included measurements for blood pressure, height, weight, vital lung capacity, sidestep test, standing vertical jump, sit-and-reach, grip strength, single leg stance test, reaction time, push-ups (men) and sit-ups (women).

The subjects performed all the tests in a gymnasium between July and August in the years 2005, 2010 and 2014. The study subjects first completed a questionnaire. Then following a 20-min rest, trained physicians measured their blood pressure using a mercury sphygmomanometer. The measurements were made in triplicate within 10-min interval with the subjects in the seated position. Arterial hypertension was determined or diagnosed by the blood pressure measured, that, systolic blood pressure $\geqslant 140 \mathrm{mmHg}$ and/or diastolic $\geqslant 90 \mathrm{mmHg}$, or current treatment with antihypertensive drugs.

The cardiorespiratory fitness (CRF) was tested using the sidestep test (TDK-2 intelligent apparatus, Ningbo Jingbei Tiandikuan Electronic Product Manufacturer). Man subjects used a $40 \mathrm{~cm}$-high footstep and woman subjects used a $35 \mathrm{~cm}$-high footstep to perform the up-anddown movement. Every subject performed up-and-down movements for about $3 \mathrm{~min}$ (90 repetitions) in rhythm to music. After the subject sat down, a finger clip was placed on the subject's middle finger from which pulse rate was displayed on the screen and recorded. Pulse rate readings

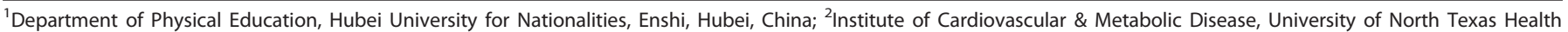

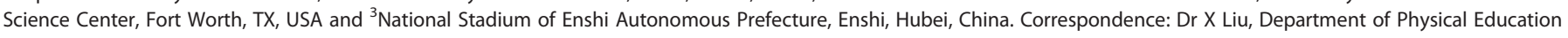
Hubei University for Nationalities Enshi, Hubei, China.

E-mail: yixuelau@163.com

Received 29 March 2017; revised 16 June 2017; accepted 30 June 2017; published online 10 August 2017 
Table 1. Classification criteria of cardiorespiratory fitness (CRF)

\begin{tabular}{|c|c|c|c|c|c|c|c|c|}
\hline \multirow[t]{2}{*}{ Age (Year) } & \multicolumn{2}{|c|}{ Lowest } & \multicolumn{2}{|c|}{ Low } & \multicolumn{2}{|c|}{ High } & \multicolumn{2}{|c|}{ Highest } \\
\hline & Female & Male & Female & Male & Female & Male & Female & Male \\
\hline $45-49$ & $\leqslant 45.6$ & $\leqslant 46.3$ & $>45.6, \leqslant 61.5$ & $>46.3, \leqslant 60.3$ & $>61.5, \leqslant 71.3$ & $>60.4, \leqslant 70.2$ & $>71.3$ & $>70.2$ \\
\hline $50-54$ & $\leqslant 43.8$ & $\leqslant 45.8$ & $>43.8, \leqslant 61.5$ & $>45.8, \leqslant 59.9$ & $>61.5, \leqslant 71.3$ & $>59.9, \leqslant 69.7$ & $>71.3$ & $>69.7$ \\
\hline $55-59$ & $\leqslant 39.8$ & $\leqslant 44.7$ & $>39.8, \leqslant 60.3$ & $>44.7, \leqslant 59.9$ & $>60.3, \leqslant 70.2$ & $>59.9, \leqslant 69.7$ & $>70.2$ & $>69.7$ \\
\hline
\end{tabular}

were taken three separate times after the completion of the sidestep exercise: between $1 \mathrm{~min}$ to $1 \mathrm{~min} 30 \mathrm{~s} ; 2 \mathrm{~min}$ to $2 \mathrm{~min} 30 \mathrm{~s}$; and $3 \mathrm{~min}$ $30 \mathrm{~s}$. The sidestep test index was calculated from the duration of up-anddown movements (in seconds) multiplied by 100 divided by the sum of three pulse rate readings. Table 1 shows the classification criteria of the index as CRF according to the Citizen Physical Health Standard established by Ministry of Education of China and the General Administration of Sport of China. ${ }^{7}$

Next, we measured the subjects' height, weight, vital lung capacity, standing vertical jump, sit-and-reach, grip strength, single leg stance test, reaction time, push-ups (for men) and sit-ups (for women). All of the testing apparatuses were made by the Shenzheng Hengkang Jiaye Limited Company, China. When the subjects were ready, the testers pressed the button to initiate the beginning of the test.

All physical fitness measurements and scoring criteria were classified according to the Citizen Physical Health Standard established by Ministry of Education of China and the General Administration of Sport of China. Each category we measured had an acceptable value range; if the total of these results fell within this range they were labelled as 'pass,' while those that did not were labelled as 'fail'.'

Body mass index (BMI) was calculated from weight (in kilograms)/ height $^{2}$ (in meter). The BMI was classified into four levels: 18.5 as underweight, 18.5-24.9 as normal weight, 25.0-29.9 as overweight and $\geqslant 30.0$ as obese.

Statistical analysis

All analyses were performed using the SPSS for Windows software package (version 18; SPSS Inc, Chicago, IL, USA). Descriptive statistics were obtained first; categorical variables were presented as the number of people (\%). Collinearity diagnostics were performed prior to further statistical analysis. A binary unconditional logistic regression model was used to analyse the independent effects of each variable. Potential risk factors included testing time, ages, nationality, gender, urban versus rural location, employment classification, education level, BMI, CRF and physical test scores. The dependent factor was 'Whether the subject is hypertensive'. Retained methods used a forward step-by-step approach. All variables significant at $P<0.05$ were reserved in the final model.

\section{RESULTS}

Prevalence and distribution of hypertension

Of the 2428 participants, 568 were classified as hypertensive, giving an overall prevalence of hypertension was $23.4 \%$. The prevalence was lower in 2005 and 2010 at $15.9 \%$ and $16.1 \%$, respectively, before doubling to $34.9 \%$ by 2014 . The prevalence was higher among women (25.9\%) than men (20.8\%). The prevalence of hypertension was lower in rural residents $(17.1 \%)$, compared to urban residents (26.7\%), see Table 2 . In regards to occupation, the prevalence of hypertension was highest among white-collar workers at $30.8 \%$, and lowest among blue-collar workers in rural areas at $17.0 \%$ (Table 2). By the level of education completed, the prevalence was highest among participants with a middle school education at $28.4 \%$, followed by those with university or higher education at $26.7 \%$, high school at $21.5 \%$ and primary school at $19.3 \%$ (Table 2). Hypertension prevalence was associated with BMI. By CRF levels, the prevalence was lowest among participants who had a highest fitness (20.2\%), followed by low fitness (22.2\%) and high

\begin{tabular}{|c|c|c|c|}
\hline Variable/Category & $\begin{array}{c}\text { Normotension } \\
\text { (\%) }\end{array}$ & $\begin{array}{l}\text { Hypertension } \\
\text { (\%) }\end{array}$ & Total \\
\hline \multicolumn{4}{|l|}{ Test time (year) } \\
\hline 2005 & $531(83.9)$ & $102(16.1)$ & 633 \\
\hline 2010 & $710(84.1)$ & $134(15.9)$ & 844 \\
\hline 2014 & $619(65.1)$ & 332 (34.9) & 951 \\
\hline \multicolumn{4}{|l|}{ Ages (years) } \\
\hline $45-49$ & $643(76.0)$ & $203(24.0)$ & 846 \\
\hline $50-54$ & 627 (76.9) & $188(23.1)$ & 815 \\
\hline $55-59$ & 590 (76.9) & $177(23.1)$ & 767 \\
\hline \multicolumn{4}{|l|}{ Nationality } \\
\hline Han & $1277(80.3)$ & $313(19.7)$ & 1590 \\
\hline Tujia & $582(69.5)$ & $255(30.5)$ & 837 \\
\hline \multicolumn{4}{|l|}{ Sex } \\
\hline Males & 949 (79.2) & $249(20.8)$ & 1198 \\
\hline Females & $911(74.1)$ & 319 (25.9) & 1230 \\
\hline \multicolumn{4}{|l|}{ Urban-rural } \\
\hline Rural & $689(82.9)$ & $142(17.1)$ & 831 \\
\hline Urban & $1171(73.3)$ & $426(26.7)$ & 1597 \\
\hline \multicolumn{4}{|l|}{ Employment classification } \\
\hline Blue-collar workers in rural & $689(83.0)$ & $141(17.0)$ & 830 \\
\hline Blue-collar workers in urban & 615 (77.4) & $180(22.6)$ & 795 \\
\hline White-collar workers & $556(69.2)$ & $247(30.8)$ & 803 \\
\hline \multicolumn{4}{|l|}{ Education } \\
\hline Primary school & $570(80.7)$ & $136(19.3)$ & 706 \\
\hline Middle school & $464(71.6)$ & $184(28.4)$ & 648 \\
\hline High school & $582(78.5)$ & $159(21.5)$ & 741 \\
\hline College & $244(73.3)$ & $89(26.7)$ & 333 \\
\hline \multicolumn{4}{|l|}{$B M I$} \\
\hline Underweight & 68 (91.9) & $6(8.1)$ & 74 \\
\hline Normal weight & $1287(82.2)$ & $278(17.8)$ & 1565 \\
\hline Overweight & $461(65.3)$ & 245 (34.7) & 706 \\
\hline Obesity & $44(53.0)$ & $39(47.0)$ & 83 \\
\hline \multicolumn{4}{|l|}{$C R F$} \\
\hline Highest & 237 (79.8) & $60(20.2)$ & 279 \\
\hline High & $417(75.0)$ & $139(25.0)$ & 556 \\
\hline Low & $1063(77.8)$ & $303(22.2)$ & 1366 \\
\hline Lowest & $110(69.6)$ & $48(30.4)$ & 158 \\
\hline \multicolumn{4}{|l|}{ Physical test } \\
\hline Pass & $1408(78.5)$ & $385(21.5)$ & 1793 \\
\hline Fail & 452 (71.2) & $183(28.8)$ & 635 \\
\hline
\end{tabular}

fitness (25.0\%); the prevalence was highest among participants with a lowest fitness at $30.4 \%$. The prevalence was higher among people who failed the physical test (28.8\%) compared to the ones who passed the test (21.5\%). 
Table 3. Risk factors associated with hypertension in binary logistic regression analysis

\begin{tabular}{|c|c|c|c|c|c|c|}
\hline \multirow[t]{2}{*}{ Risk factors } & \multirow[t]{2}{*}{ B } & \multirow[t]{2}{*}{ s.e. } & \multirow[t]{2}{*}{ P-value } & \multirow[t]{2}{*}{$O R$} & \multicolumn{2}{|c|}{$\begin{array}{l}95 \% \mathrm{Cl} \\
\text { for OR }\end{array}$} \\
\hline & & & & & Lower & Upper \\
\hline \multicolumn{7}{|l|}{ Test time } \\
\hline \multicolumn{7}{|l|}{2014} \\
\hline 2005 & -1.107 & 0.139 & 0.001 & 0.330 & 0.252 & 0.434 \\
\hline 2010 & -1.136 & 0.128 & 0.001 & 0.321 & 0.250 & 0.412 \\
\hline Nationality & 0.054 & 0.008 & 0.001 & 1.055 & 1.039 & 1.072 \\
\hline Sex & 0.264 & 0.107 & 0.014 & 1.302 & 1.054 & 1.607 \\
\hline \multicolumn{7}{|l|}{ Education } \\
\hline \multicolumn{7}{|l|}{ College } \\
\hline Primary school & 0.108 & 0.194 & 0.577 & 1.114 & 0.762 & 1.628 \\
\hline Middle school & 0.428 & 0.182 & 0.019 & 1.535 & 1.074 & 2.194 \\
\hline High school & -0.121 & 0.171 & 0.480 & 0.886 & .634 & 1.239 \\
\hline \multicolumn{7}{|l|}{ Employment classification } \\
\hline \multicolumn{7}{|l|}{ White-collar workers } \\
\hline $\begin{array}{l}\text { Blue-collar workers } \\
\text { in rural }\end{array}$ & -0.870 & 0.148 & 0.001 & 0.419 & 0.314 & 0.559 \\
\hline $\begin{array}{l}\text { Blue-collar workers } \\
\text { in urban }\end{array}$ & -0.382 & 0.131 & 0.004 & 0.682 & 0.528 & 0.882 \\
\hline \multicolumn{7}{|l|}{$B M I\left(\mathrm{~kg} \mathrm{~m}^{-2}\right)$} \\
\hline \multicolumn{7}{|l|}{ Normal weight } \\
\hline Underweight & -0.782 & 0.482 & 0.105 & 0.457 & 0.178 & 1.177 \\
\hline Overweight & 0.753 & 0.111 & 0.001 & 2.124 & 1.710 & 2.639 \\
\hline Obesity & 1.244 & 0.251 & 0.001 & 3.470 & 2.123 & 5.673 \\
\hline \multicolumn{7}{|l|}{$C R F$} \\
\hline \multicolumn{7}{|l|}{ High } \\
\hline Highest & 0.140 & 0.186 & 0.453 & 1.150 & 0.799 & 1.655 \\
\hline Low & 0.401 & 0.171 & 0.019 & 1.493 & 1.069 & 2.087 \\
\hline Lowest & 0.910 & 0.247 & 0.001 & 2.483 & 1.530 & 4.031 \\
\hline Constant & -1.675 & 0.274 & 0.001 & 0.187 & & \\
\hline
\end{tabular}

Abbreviations: BMI, body mass index, CRF, cardiorespiratory fitness.

Risk factors associated with hypertension in binary logistic regression analysis

Table 3 shows the risk factors for hypertension, which were initially analysed with time stratification. Since the risk factors that predicted the hypertensive prevalence were similar in the logistic regression models, the major predictors were merged together in the discussion for simplicity reason. CRF was inversely related to hypertension. Compared the high level of CRF, people with the lowest level of CRF had a 2.483 -fold risk for hypertension $(95 \% \mathrm{Cl}$, $1.530-4.031 ; P=0.001$ ), and people with low level of CRF had a 1.493-fold risk for hypertension $(95 \% \mathrm{Cl}, 1.069-2.087 ; P=0.019)$, but the highest level of CRF group had no significant difference with the high level of CRF $(95 \% \mathrm{Cl}, 0.799-1.655 ; P=0.453)$; the prevalence of hypertension was the highest in the year 2014 and they were 67.0 and $67.9 \%$ more likely for having hypertension than the same age people in 2005 and 2010. Tujia-Nationality people had an increased risk for having hypertension with OR: $1.055,95 \% \mathrm{Cl}, 1.039-1.072(P=0.001)$, compared to Han people; middle-age women had a $30.2 \%$ higher risk for hypertension (95\% Cl, 1.054-1. 607; $P=0.014)$ than their man counterparts. By level of education attained, groups with no higher than a middle school education had a $53.5 \%$ higher risk for hypertension (95\% Cl, 1.074-2.194; $P=0.019$ ) than the ones who attained college education. White-collar workers had a $58.1 \%$ and $31.8 \%$ higher risk for hypertension than blue-collar workers in rural and urban areas, respectively. Compared with the normal weight group (BMI between 18.5-25.0 $\mathrm{kg} \mathrm{m}^{-2}$ ), obese group (BMI $\geqslant 30.0 \mathrm{~kg} \mathrm{~m}^{-2}$ ) and overweight group (BMI between 25.0 and $29.9 \mathrm{~kg} \mathrm{~m}^{-2}$ ) had 3.470-fold and 2.124-fold risk for hypertension, respectively.

\section{DISCUSSION}

This study indicated that the prevalence of hypertension suddenly increased from 2011 to 2014 in the Tujia settlement in Hubei province of China. For these middle-aged people, the main risk factors for developing hypertension were found to be sex (as woman), Tujia-nationality minority, white-collar workers, the overweight/obese, those with a middle school education and those with the lowest CRF.

We found the prevalence of hypertension suddenly increased from 15.9 to $34.9 \%$ between 2010 and 2014 in this area, which was even higher than the $32.4 \%$ found within the age-matched group in America between 2011 and $2012 .^{8}$ It was a special time for this area in 2010-2014, because the highway and railway had their first routes in 2009 and 2010, leading to rapid development of the local economy. However, healthy lifestyles and health education did not progress at the same pace, which led to the chronic disease increase. ${ }^{9}$

The prevalence of hypertension in middle-aged women was higher, which seemed to be related to a menopause. ${ }^{10}$ An Italian study $^{11}$ showed a higher frequency in postmenopausal women $(64.1 \%)$ as compared with perimenopausal and premenopausal women, independent of age and BMI. Judith et al. ${ }^{12}$ found the relationship between hypertension in menopausal versus nonmenopausal women (70.3\% versus $29.0 \%)$. In the present study, we found that women had a $30.2 \%$ higher risk for hypertension (95\% Cl, 1.054-1.607; $P=0.014$ ) than men, which indicated menopausal women had a higher prevalence of hypertension than men as they entered in the middle age. These findings suggest that sex hormones have a prominent role in preventing hypertension ${ }^{13}$ for women.

Since the 1980s, work-related stressors have become recognized as important risk factors for having cardiovascular disease and hypertension. ${ }^{14}$ Workers with lower socioeconomic status (variously defined by education, income or occupation) have been found to have higher age-adjusted mean systolic blood pressure (by $2-3 \mathrm{mmHg}$ ) or prevalence of hypertension than employees in higher socioeconomic status groups. ${ }^{15}$ Other studies found somewhat different results. Landsbergis et al. ${ }^{14}$ found workers in blue-collar and sales/office jobs had $2-4 \mathrm{mmHg}$ higher systolic blood pressure than workers in management and professional jobs. Our data were consistent with the study of Landsberqis et al., ${ }^{14}$ which suggested that white-collar workers had a $58.1 \%$ and $31.8 \%$ higher risk for hypertension than blue-collar workers in rural and urban areas, respectively. These data indicate a greater work-related stress in white-collar workers. $^{16}$

Associations between educational status and the development of hypertension have been examined in several studies published over the past decade. The US National Bureau of Economic Research stated that each additional 4 years of education lowered all-cause mortality by almost $1.8 \%$ and reduced the risk of heart disease by $2.2 \%{ }^{17}$ The present study found that the relationship between education and hypertension was a Bell-shaped pattern (Table 3 ), showing people who attained a middle school education had a $53.5 \%$ higher risk for having hypertension $(95 \% \mathrm{Cl}, 1.074-2.194 ; P=0.019)$ than those who attained college education. People who did not surpass primary school generally took part in more physically active jobs, which might cause them to have a lower incidence of coronary heart disease than among those whose jobs required little or no physical activity. On the other hand, the residents who received higher-level educational status such as college 
and graduate school tended to have more opportunity to access health knowledge and health care, which could lead to low incidences of hypertension.

The worldwide pandemic of overweight and obesity is associated with increased prevalence of hypertension and other cardiovascular diseases. It has been shown that adipose tissue can elevate circulating aldosterone. ${ }^{18,19}$ Over activation of the sympathetic nervous system is a common feature of obesity, which is widely recognized as a major contributor to the development of hypertension. ${ }^{20}$ Our study confirmed the previous studies ${ }^{1,21,22}$ and indicated that obesity and overweight people had elevated the risk by 3.470-fold and 2.124-fold, respectively, for having hypertension compared to the individuals with normal weight in the area.

CRF provides protective influence against cardiovascular diseases and significantly attenuates the rise in blood pressure over the life span. Thus, the examination of serial changes in CRF as it relates to incidental hypertension is of considerable interest. ${ }^{23}$ Aerobic exercises may prevent increases in blood pressure through beneficial alterations in insulin sensitivity and autonomic nervous system function. ${ }^{24}$ Several previous studies have reported the associations between changes in CRF over time and the risk of developing future hypertension. ${ }^{20,23,25}$ Lee et al. $^{25}$ found that men with lower estimated CRF between initial and follow-up examinations had a higher risk of developing hypertension than men who maintained or improved CRF during the 6-year interim between assessments. Jae et al. $^{23}$ found the prevalence of hypertension in lower CRF people was 4.33-folder than the highest CRF people. Recently, Xu et al. ${ }^{20}$ reported that 1 -year aerobic exercise training significantly increased peak oxygen uptake and decreased both systolic and diastolic blood pressure in a group of elderly adults. Our results were consistent with these previous studies and further found there was no difference on the risk of hypertension between high levels of CRF. The hypertension prevalence was higher among people who failed the physical test at $28.8 \%$ than among the ones who passed the test at $21.5 \%$. However, it was not included as the risk factor in the logistic model, suggesting that the cardiorespiratory function or aerobic capacity was a more important predictor than the physical fitness in preventing hypertension.

Many studies found the prevalence of hypertension was dissimilar among countries and ethnicities. ${ }^{26,27}$ In the present study, all of the subjects with different nationalities lived in the same location for many years, though this area is the settlement of Tujia people. Our data suggested that Tujia minority had an increased risk for having hypertension with OR: $1.055(95 \% \mathrm{Cl}$, $1.039-1.072, P=0.001$ ) compared to Han people. Future study is needed to determine whether the predisposition to developing hypertension in Tujia minority is influenced by genetic and/or epigenetic factors. ${ }^{28}$

In the present study, we were unable to find a correlation between hypertension and some other factors that have often been associated with hypertension, such as an urbanrural setting ${ }^{29}$ and age. ${ }^{30}$ This indicates that there might be other risk factors for developing hypertension existed in this area.

The main limitation of the present study was that we randomly selected the volunteer subjects who responded to the advertisement, which could not avoid the self-selection bias.

\section{CONCLUSION}

The prevalence of hypertension in the middle-aged individuals was higher during 2011-2014 in the Tujia settlement of the southwest Hubei province in China. The main risk factors for developing hypertension included sex (as women), Tujianationality minority, white-collar workers, the overweight/obese, those with a middle school education, and those with the lowest CRF.

What is known about the topic?

- Hypertension is one of the most common medical disorders, Hypertension affects one in four adults worldwide, with a lifetime prevalence that may exceed $90 \%$. It is associated with increased risks of stroke, ischaemic heart disease, heart failure, kidney disease and premature mortality.

- There are many factors in the aetiology of essential hypertension.

- There are many factors in the aetiology of essential hypertension, such as ages, sex, urban-rural and so on. However, it can vary between ethnicities, countries, or even among regions within the same country.

What this study adds?

- The prevalence of hypertension in the middle-aged population is higher during 2011-2014 in the Tujia settlement of the southwest Hubei province in China.

- There was a sudden increase in the prevalence of hypertension from 15.9 to $34.9 \%$ between 2010 and 2014 in this area, which was even higher than the $32.4 \%$ found within the age-matched group in America between 2011 and 2012.

- Tujia-nationality minority has a significantly higher risk for having hypertension (OR: 1.055 and $95 \% \mathrm{Cl}, 1.039-1.072 ; P=0.001$ ) than Han people. This ethnicity difference is a risk factor which predicts the prevalence of hypertension in the middle-aged population of the area.

\section{CONFLICT OF INTEREST}

The authors declare conflict of interest.

\section{ACKNOWLEDGEMENTS}

We thank our volunteer subjects for their cheerful cooperation during the study. Funding for $\mathrm{XL}$ was provided by nature science funding from Hubei Provincial Department of Education (Q20131906), China.

\section{REFERENCES}

1 Xu X, Byles J, Shi Z, Mcelduff P, Hall J. Dietary pattern transitions, and the associations with BMI, waist circumference, weight and hypertension in a 7-year follow-up among the older Chinese population: a longitudinal study. BMC Public Health 2016; 16: 743.

2 Yan YX, Dong J, Liu YQ, Yang XH, Li M, Shia G et al. Association of suboptimal health status and cardiovascular risk factors in urban Chinese workers. J Urban Health 2012; 89(2): 329-338.

3 Rodriguez F, Hicks LS, Lopez L. Association of acculturation and country of origin with self-reported hypertension and diabetes in a heterogeneous Hispanic population. BMC Public Health 2012; 12: 768.

4 Guwatudde D, Nankya-Mutyoba J, Kalyesubula R, Laurence C, Adebamowo C, Ajayi I et al. The burden of hypertension in sub-Saharan Africa: a four-country cross sectional study. BMC Public Health 2015; 15: 1211.

5 Kumara WA, Perera T, Dissanayake M, Ranasinghe P, Constantine GR. Prevalence and risk factors for resistant hypertension among hypertensive patients from a developing country. BMC Res Notes 2013; 6: 373.

6 Liang XY, Nie SF, Qu KY, Peng XX, Wei S, Zhu GB et al. Evaluation of health-related quality of life among hypertensive patients in a rural area, PR China. J Hum Hypertens 2006; 20(3): 227-229.

7 Adults physical health standard. Ministry of Education of China and General Administration of Sport of China. Beijing, 2008.

8 QuickStats: age-adjusted prevalence of hypertension treatment among adults aged $\geqslant 18$ years with hypertension, by sex and race/ethnicity-national health and nutrition examination survey, United States, 2011-2014. MMWR Morb Mortal Wkly Rep 2016; 65(21): 553.

9 Tang Z, Zhou T, Luo Y, Xie C, Huo D, Tao L et al. Risk factors for cerebrovascular disease mortality among the elderly in Beijing: a competing risk analysis. PLOS ONE 2014; 9(2): e87884. 
10 Wang Y, Klaric L, Yu X, Thaqi K, Dong J, Novokmet $M$ et al. The association between glycosylation of immunoglobulin $\mathrm{G}$ and hypertension: a multiple ethnic cross-sectional study. Medicine 2016; 95(17): e3379.

11 Zanchetti A, Facchetti R, Cesana GC, Modena MG, Pirrelli A, Sega R. Menopauserelated blood pressure increase and its relationship to age and body mass index: the SIMONA epidemiological study. J Hypertens 2005; 23(12): 2269-2276.

12 Zilberman JM, Cerezo GH, Del Sueldo M, Fernandez-Perez C, Martell-Claros N, Vicario A. Association between hypertension, menopause, and cognition in women. J Clin Hypertens 2015; 17(12): 970-976.

13 Tagle R, Acevedo M, Valdes G. Hypertension in women. Rev Med Chil 2013; 141(2): 237-247.

14 Landsbergis PA, Diez-Roux AV, Fujishiro K, Baron S, Kaufman JD, Meyer JD et al. Job strain, occupational category, systolic blood pressure, and hypertension prevalence: the multi-ethnic study of atherosclerosis. J Occup Environ Med 2015; 57(11): 1178-1184.

15 Keenan NL, Rosendorf KA. Prevalence of hypertension and controlled hypertension-United States, 2005-2008. MMWR Suppl 2011; 60(1): 94-97.

16 Guwatudde D, Mutungi G, Wesonga R, Kajjura R, Kasule H, Muwonge J et al. The epidemiology of hypertension in Uganda: findings from the National Non-Communicable Diseases Risk Factor Survey. PLOS ONE 2015; 10(9): e0138991.

17 Notara V, Panagiotakos DB, Kogias Y, Stravopodis P, Antonoulas A, Zombolos S et al. The impact of educational status on 10-year (2004-2014) cardiovascular disease prognosis and all-cause mortality among acute coronary syndrome patients in the Greek Acute Coronary Syndrome (GREECS) Longitudinal Study. $J$ Prev Med Public Health 2016; 49(4): 220-229.

18 Lambert E, Sari Cl, Dawood T, Nguyen J, Mcgrane M, Eikelis N et al. Sympathetic nervous system activity is associated with obesity-induced subclinical organ damage in young adults. Hypertension 2010; 56(3): 351-358.

19 Hirooka Y, Kishi T, Ito K, Sunagawa K. Potential clinical application of recently discovered brain mechanisms involved in hypertension. Hypertension 2013; 62(6): 995-1002.

20 Xu D, Wang H, Chen S, Ross S, Liu H, Olivencia-Yurvati A et al. Aerobic exercise training improves orthostatic tolerance in aging humans. Med Sci Sports Exerc 2017; 49(4): 728-735.

21 Crump C, Sundquist J, Winkleby MA, Sundquist K. Interactive effects of physical fitness and body mass index on the risk of hypertension. JAMA Intern Med 2016; 176(2): 210-216.
22 Szklarska A, Lipowicz A. BMI, hypertension and low bone mineral density in adult men and women. Homo 2012; 63(4): 282-291.

23 Jae SY, Kurl S, Franklin BA, Laukkanen JA. Changes in cardiorespiratory fitness predict incident hypertension: a population-based long-term study. Am J Hum Biol. 2017; 29: e22932.

24 Moraes-Silva IC, Mostarda C, Moreira ED, Silva KA, Dos Santos F, De Angelis K et al. Preventive role of exercise training in autonomic, hemodynamic, and metabolic parameters in rats under high risk of metabolic syndrome development. J Appl Physiol 2013; 114(6): 786-791.

25 Lee DC, Sui X, Church TS, Lavie CJ, Jackson AS, Blair SN. Changes in fitness and fatness on the development of cardiovascular disease risk factors hypertension, metabolic syndrome, and hypercholesterolemia. J Am Coll Cardiol 2012; 59(7): 665-672.

26 Bentley-Lewis R, Powe C, Ankers E, Wenger J, Ecker J, Thadhani R. Effect of race/ethnicity on hypertension risk subsequent to gestational diabetes mellitus. Am J Cardiol 2014; 113(8): 1364-1370.

27 Hull S, Dreyer G, Badrick E, Chesser A, Yaqoob MM. The relationship of ethnicity to the prevalence and management of hypertension and associated chronic kidney disease. BMC Nephrol 2011; 12: 41.

28 Yoshida M, Watanabe Y, Yamanishi K, Yamashita A, Yamamoto H, Okuzaki D et al. Analysis of genes causing hypertension and stroke in spontaneously hypertensive rats: gene expression profiles in the brain. Int J Mol Med 2014; 33(4): 887-896.

29 Li J, Shi L, Li S, Xu L, Qin W, Wang H. Urban-rural disparities in hypertension prevalence, detection, and medication use among Chinese Adults from 1993 to 2011. Int J Equity Health 2017; 16(1): 50.

30 Hosseini M, Yousefifard M, Baikpour M, Rafei A, Fayaz M, Heshmat R et al. Twenty-year dynamics of hypertension in Iranian adults: age, period, and cohort analysis. J Am Soc Hypertens 2015; 9(12): 925-934.

(c) (1) This work is licensed under a Creative Commons AttributionNonCommercial-ShareAlike 4.0 International License. The images or other third party material in this article are included in the article's Creative Commons license, unless indicated otherwise in the credit line; if the material is not included under the Creative Commons license, users will need to obtain permission from the license holder to reproduce the material. To view a copy of this license, visit http:// creativecommons.org/licenses/by-nc-sa/4.0/

(c) The Author(s) 2017 